\title{
VIDAS ANÓNIMAS CON SUS INFINITAS RAÍCES: MISERICORDIA EN LAS LECTURAS DE MARÍA ZAMBRANO
}

\section{UNKNOWN LIVES WITH INFINITE ROOTS: MISERICORDIA READ BY MARÍA ZAMBRANO}

\author{
Pablo Muñoz Covarrubias \\ Universidad Autónoma Metropolitana-Iztapalapa \\ juanpablomunozcovarrubias@gmail.com \\ orcid: 0000-0002-3950-1123
}

Resumen: La España de Galdós de María Zambrano se publicó en 1960. Sin embargo, se trata de un volumen escrito a lo largo de varias décadas. La escritora y filósofa ya había publicado en Hora de España, en 1938, un ensayo en que destacaba la importancia de Misericordia y la relevancia de Galdós como escritor. La intención de las siguientes páginas es exponer las maneras en que Zambrano leyó y convirtió en símbolos los componentes de la novela galdosiana, al tiempo que se esbozan algunas comparaciones entre sus diversas perspectivas y las opiniones de otros escritores acerca del propio Galdós. Esta metodología permitirá comprender la originalidad del planteamiento de Zambrano.

Palabras clave: María Zambrano; Pérez Galdós; Misericordia; literatura española; narrativa del s. XIx.

Abstract: María Zambrano's La España de Galdós was first published in 1960. Nevertheless, it was a work in progress written over the course of several decades. The essayist and philosopher published an essay in Hora de España as early as 1938 in which she had pinpointed the importance of Misericordia and the relevance of Galdós as a writer. The purpose of the following pages is to understand the way in which Zambrano read and symbolized the component elements of this novel. The article also compares aspects of Zambrano's reading of this book with the opinions expressed by other intellectuals. In this way the originality of her study will be more easily appreciated.

Keywords: María Zambrano; Pérez Galdós; Misericordia; Spanish literature; $19^{\text {th }}$ century narrative.

Recepción: 13 de marzo de 2019; aceptación: 3 de septiembre de 2019. 
Debéis entender que el hombre puede tener amor sin caridad, pero no caridad sin amor.

Arnau de Vilanova, Tratado de la caridad

\section{INTRODUCGIÓN}

Son muchas las pruebas que pueden servirnos para demostrar el interés que María Zambrano sintió no solamente por la obra literaria de Benito Pérez Galdós, sino también por la figura del autor canario ${ }^{1}$. Como lo ha establecido Goretti Ramírez (2004) en un extenso trabajo sobre la crítica literaria ejercida por la autora veleña, dos fueron los escritores en quienes la filósofa puso una palpable atención a lo largo de su trayectoria: Miguel de Cervantes y Benito Pérez Galdós.

Galdós acompañó a Zambrano desde los años de su juventud en España, durante el exilio y también, finalmente, en los años del regreso. Ramírez observa que "Galdós fue el autor español a quien María Zambrano dedicó mayor número de páginas, y con mayor constancia” (p. 127). Incluso, la filósofa dedicó un libro completo al estudio de su obra, un libro que se fue construyendo en distintas épocas de su vida; y que, por tanto, nos revela los elementos constantes y los elementos cambiantes de su visión. Cualquier trabajo que busque rastrear la importancia que posee la obra de Galdós en ese otro universo inconmensurable que es la obra de Zambrano tendría que recorrer las diversas etapas de la producción prosística de nuestra

${ }^{1}$ Como se aclara en el anejo correspondiente de las Obras completas, t. 3, los textos que Zambrano dedicó al estudio de la obra y la figura de Galdós fueron escritos en muy distintas décadas (desde finales de los años treinta hasta llegar a los años ochenta). En los respectivos anejos (pp. 1291-1297), puede encontrarse la bibliografía de las obras que Zambrano dedicó a Pérez Galdós en las diversas etapas de su producción. La primera edición del libro que aquí centralmente nos interesa -La España de Galdós-apareció en 1960 y la última en 1989. Es importante señalar que los dos grandes textos que la filósofa dedicó al estudio de la novela Misericordia fueron ya incluidos en ese volumen desde la edición primera. "Misericordia" apareció originalmente en la histórica revista Hora de España en 1938. Un fragmento de "Nina o la Misericordia" fue incluido en la revista Ínsula en 1959 antes de incorporarse al libro señalado. Para efectos de este trabajo, he manejado la edición de las Obras completas, t. 3, correspondiente a 2014. 
autora $^{2}$. Y partir sobre todo, según creo, de un examen general de la situación de Galdós entre sus contemporáneos y entre los principales escritores de las generaciones previas, las generaciones más o menos inmediatas a la suya, las que muchas veces, sí, lo ensalzaron, pero que también -circunstancialmente-ignoraron al autor o lo despreciaron por ese papel que injustamente le confirieron como el supuesto garbancero de la literatura española, tal y como lo planteó Ramón María del Valle Inclán en Luces de Bohemia. Zambrano, por su parte, llegó a hablar de un Galdós "olvidado y desdeñado" hacia 1938, lo cual denota bien su reconocimiento del abandono o del desinterés que suscitaban las páginas del novelista, de ese vaivén que iban sufriendo por la variable "distancia estética" que provocaban sus páginas; pues tal y como lo apuntó Hans Robert Jauss (2000) en un texto fundamental para los estudios filológicos contemporáneos, "la obra literaria no es un objeto existente para sí que ofrezca a cada observador el mismo aspecto en cualquier momento... Es más bien como una partitura adaptada a la resonancia siempre renovada de la lectura, que redime el texto de la materia de las palabras y lo trae a la existencia actual" (p. 161). Todavía en un artículo aparecido en 1986, Zambrano concluye que "los intelectuales, no, los intelectuales no siempre lo entendieron [a Pérez Galdós] y él tampoco pareció buscarlo" (2009, p. 203). Sin embargo, sus exequias, como también nos lo recuerda Zambrano en el mismo artículo, fueron multitudinarias: el pueblo, en apariencia, sí supo reconocer su lugar sin acaso haber leído sus novelas.

Al acercarse a la obra de Pérez Galdós, Zambrano tocó muchos de los temas centrales que la ocuparon frecuentemente a lo largo de su vida intelectual; y en ese sentido su lectura de Galdós fue un inmejorable vehículo para ilustrar sus ideas de modo práctico y tangible: España no sólo como nación o pue-

${ }^{2}$ Son varios los trabajos de investigación y ensayos que se han dedicado, dentro de la ingente bibliografía sobre Zambrano, al estudio de su concepción de la figura y de la obra de Pérez Galdós. El más relevante acaso sea el capítulo que a este asunto dedica ANA BundGÅrd (2000, pp. 343-382). Otros estudios que pueden consultarse sobre el tema son los siguientes: Sánchez-Gey Venegas 1992 y 2009; Cruz Ayuso 1999; Sánchez Benítez 2002; Mora García 2004; Thion Soriano-Mollá 2008; y Rivara Kamaji 2014. Adicionalmente, también puede consultarse el ensayo de MaILlard García (2014) con que se prologa La España de Galdós en la edición de las Obras completas, t. 3. 
blo, sino más bien como proyecto poético, sueño y posibilidad; la razón poética como el corazón indudable de su obra originalísima; las posibilidades de la convivencia entre la realidad, la verdad, la historia, la tragedia y la poesía; la tradición hispánica y la tradición europea en conflicto permanente desde los albores de la modernidad; las andanzas de don Quijote como personaje y como símbolo; las vertientes del realismo europeo y-en especial-del realismo español.

Como ha sido ampliamente reconocido, con Pérez Galdós la estética realista alcanzará su clímax en España, ese realismo del cual Azorín (1938) llegó a observar que poseyó la capacidad para representar, por fin, las cosas del mundo en su real espiritualidad: "El realismo moderno -implantado aquí por Galdós- estudia por lo tanto no sólo los casos en sí, como lo hacían los antiguos, sino el ambiente espiritual de las cosas" (p. 127). Para Azorín, la obra de Pérez Galdós cumplió bien con su objetivo, pues fue capaz de revelar España a los españoles. Por supuesto, en la cita parece Azorín proyectar parcialmente algo de su vocación personal sobre la obra galdosiana; y hay que agregar, sin embargo, que para Zambrano la obra de Galdós habría cumplido con esa misma función reveladora del "ambiente espiritual de las cosas". Para ella, el realismo se presenta, incluso, como un modo especial con que conceptuar no sólo un momento determinado en la historia de los estilos del arte, sino más bien un ámbito tan espacioso como lo sería el universo entero; en su propuesta, el realismo es, en términos generales, "una forma de conocimiento". En el ensayo que la filósofa dedicó en 1938 al comentario de Misericordia, advertirá, por ejemplo, que "el realismo español será algo mucho más que una cualidad y más decisivo que un estilo; será simplemente la actualización de este género de saber en el clima hostil de una cultura de origen limitadamente racionalista que va agotando su ciclo" (2014, t. 3, p. 572). El realismo será para ella entonces un recurso más con que desplazar la razón moderna -europeísta- y preferir la razón poética como metodología de acercamiento a la realidad, a su conocimiento verdadero; rebasaría de este modo la noción ofrecida por su maestro José Ortega y Gasset del realismo como la expresión de cierto impresionismo, como una perspectiva de las cosas, una manera específica de observarlas. En este punto, creo que será necesario recordar la función que Zambrano concedió no sólo a la poesía, sino también al género novelístico como ese privilegiado espacio tex- 
tual para la revelación, para la puesta en marcha de la "razón poética", tal y como ella lo explicó en algunas páginas de Pensamiento y poesía en la vida española (1939), páginas publicadas, por supuesto, ya en la etapa del exilio, pero que alcanzan a iluminar el trabajo realizado previamente en España:

La necesidad ineludible de saber que tiene todo hombre y todo pueblo sobre las cosas que más le importan, se ha satisfecho en España en formas diríamos "sacramentales", con la novela y su género máximo, la poesía. Novela y poesía funcionan, sin duda, como formas de conocimiento en las que se encuentra el pensamiento disuelto, disperso, extendido; por las que corre el saber sobre los temas esenciales y últimos sin revestirse de autoridad alguna, sin dogmatizarse, tan libre que puede parecer extraviado (2015b, t. 1, p. 577).

\section{ENTRE El olvido Y EL REGUERdo: Miguel de UnAmuno}

Durante su vida, Pérez Galdós alcanzó, si no el reconocimiento universal, sí la consideración generalizada de que su proyecto literario se había convertido en una suerte de admirable monumento por donde transitaba la historia española más o menos reciente y donde había logrado, por fin, vivir y convivir un sinnúmero de representaciones humanas y sociales de su patria. Por ello, no dejan de asombrar los juicios sumarios con que su obra fue fustigada a partir de su muerte en el año de 1920 -e incluso antes- por algunos de los más importantes y representativos pensadores de la época. Como bien lo ha observado Paciencia Ontañón (1999, p. 225), “en 1920, cuando Galdós muere, comienza a ser olvidado; en realidad se prolonga un silencio que, lentamente, se había iniciado bastante tiempo antes. Los lectores han dejado de interesarse en él y la crítica lo ignora”. Si bien María Zambrano escribirá su primer ensayo acerca de la obra de Galdós durante la segunda mitad de la década del treinta, hacia el final de la Guerra Civil, la filósofa tuvo que conocer las ideas que se venían manifestando y repitiéndose acerca de la obra del escritor canario durante las décadas anteriores: la forma en que había sido interpretada la partitura de sus textos, si nos atenemos a la imagen propuesta por Jauss. Un escritor que influyó fuertemente en su lectura, según creo, de la obra de Pérez Galdós, sobre todo por la útil 
concepción de lo "intrahistórico", fue Miguel de Unamuno; lo curioso es que Unamuno supo mantener una oposición radical en contra de las concepciones estéticas y éticas del escritor, de su idea de la vida y del hombre en la sociedad. Para Unamuno, Pérez Galdós fue un "literato laboriosísimo" y poco más que eso.

En un artículo periodístico muchas veces recordado por los estudiosos de la Generación del 98, un artículo cuya funcionalidad elegíaca se ve pronto rebasada por su actitud ultracrítica -"La sociedad galdosiana"-, Unamuno planteó de forma contundente su desacuerdo absoluto con los procedimientos literarios del autor de Misericordia:

Apenas hay en la obra novelesca y dramática de Galdós una robusta y poderosa personalidad individual, uno de esos héroes que luchan contra el trágico destino y se crean un mundo para sí, para sí mismos, un Hamlet, un Segismundo, un Don Quijote, un Tenorio, un Fausto, un Brand o un Juan José. Es que Galdós no les encontró en el mundo en que el destino le hizo vivir (1966 [1920], t. 3, p. 1204).

Precisamente, esto será lo que Zambrano sí encontrará en la obra de Galdós, particularmente en las páginas de la novela Misericordia: la construcción de un personaje cuya enorme vitalidad, cuyo heroísmo, cuya ejemplaridad acaso cristiana, sólo podrán explicarse por medio de la consideración de virtudes heroicas como lo serían la paciencia, la caridad y el amor y la misericordia, misericordia que deposita en todos los desprotegidos sin importar su procedencia social, en doña Paca, en el caballero Ponte, en Almudena, en todo ser sufriente que se le cruce por los polvorosos caminos castellanos. De hecho, será Benigna la figura heroica que se encargue de luchar, a brazo partido, en contra, si no de las imposiciones puramente trágicas del destino, sí para favorecer a su ama después de que ésta hubiese caído en desgracia por su incapacidad para administrar los bienes que heredó: su destino trágico -y muy modernoserá entonces el resultado de la poca inteligencia del individuo en un contexto social y económico más bien mediocre y descontrolado (el de la Restauración borbónica), en que el dinero -la contabilización del mismo- se convierte prácticamente en la máxima obsesión. Nina tendrá que conseguir siempre lo que falte para evitar el hambre y la humillación; y tendrá que desplazarse constantemente de un sitio a otro buscando satisfa- 
cer las necesidades de sus patrones. Por ello, se ha reconocido en su caracterización elementos que vivamente nos recuerdan el comportamiento del pícaro: por su movimiento constante.

Zambrano apuntó en "La reforma del entendimiento español" (1937) lo siguiente a propósito de la cercanía entre la novela cervantina, la novela galdosiana y el relato picaresco: "La novela, desde Cervantes a Galdós, pasando por la picaresca, nos trae el verdadero alimento intelectual del español en su horror por el sistema filosófico; es en ella donde hemos de ver lo que el español veía y sabía también lo que era. También de lo que carecía" (2015, t. 1, p. 214). Ese "alimento espiritual" está, en la novela Misericordia, en el personaje de Nina, en esa picara que veremos ir y venir, negociar, dialogar y resolver los problemas más urgentes de orden económico, pero para el beneficio de otros -Zambrano la simbolizará, por cierto, como una paloma por sus movimientos constantes 3 . En ese sentido, es un personaje que no se escapa de esa conducta clásica que ha sido definida por los especialistas en la obra de Galdós como la "pasión crematística", pero sin ningún rasgo, por lo demás, de egoísmo o ambición. Si bien no es un personaje clásicamente trágico, como los que enlista Unamuno en el artículo suyo, sí se trata de una figura relevante por los motivos y razones que le confieren una dimensión trascendente. Veamos, por cierto, cómo Zambrano describe precisamente el continuo trajinar de Nina y la trascendencia que tendrá el hecho de ir contando:

3 Acerca de la simbología de la paloma, valdrá la pena tomar en cuenta el artículo de Francisco Chica (1999). En la primera parte del artículo, el investigador presenta y edita algunas cartas intercambiadas entre Emilio Prados y María Zambrano. De forma recurrente, reaparece la paloma en tales misivas (y también en el poemario de 1957 de Prados: Circuncisión del sueño). Chica ha observado lo siguiente: "Aunque en las cartas adquiere valores muy diversos (renuncia, pureza espiritual, afecto protector), está ligada [la paloma] a una idea sublimada del amor que trasciende lo individual, y sirve sobre todo para perfilar el concepto de mística que comparten ambos escritores: el cruce unificador en el que quedan detenidos espacio y tiempo" (p. 255). Es interesante que algunos de estos elementos también los posea la interpretación que Zambrano elabora de Benigna: sobre todo, un espíritu maternal, generoso y protector (en la correspondencia citada se vincula la figura del ave con la madre de la autora). Por cierto: en una de las cartas que la filósofa dirigió a Prados desde Roma (la del 7 de mayo de 1960), anunciará la publicación de La España de Galdós, lo cual nos hace pensar en la manera en que la imagen del pájaro navegó y se transfirió en los diversos textos señalados. 
Trabajaba, mendigaba de la más difícil manera, de incógnito. Y el andar en trampas y enredos era en ella fatiga, una innumerable fatiga por los infiernos de la cantidad: los días, las horas que se nombraban como unidades de tiempo, abren sus entrañas en eternidades, en vacíos, en instantes que se consumen sin pasar. El tiempo se hace infierno para quien tiene que resolver el imposible de sacar de la nada un algo para vivir (2014a [1960], p. 554).

Aquello que suponga una numeración, aquello que venga acompañado por una cifra, será bajo esta perspectiva de lo infernal, el "infierno de la cantidad". Zambrano convertirá al personaje de Misericordia en un ser que atravesará el infierno, un poco a la manera de los grandes personajes de la literatura clásica -y de la mitología- que tuvieron que bajar al Hades; pero en este caso, y así lo interpreta la pensadora, ese espacio tortuoso y de castigo será el mundo de la España de la Restauración. Si bien Nina no posee el carácter ni tampoco la fuerza del personaje hamletiano, como quizás lo hubiese demandado Unamuno, sí es una mujer que se encuentra situada en los terribles infiernos, reitero, de la cantidad, en ese deseo de "sacar de la nada un algo para vivir".

En el mismo artículo previamente citado ("La sociedad galdosiana”), Unamuno achacará a Galdós la imposibilidad de haber dotado sus textos con aquello que permitiría identificar una vertiente psicológica o sociológica, ya que, según él, el autor canario "no refleja una sociedad, sino una muchedumbre” (p. 1204). Si bien Pérez Galdós nos va a entregar un retrato de una sociedad constituida por estratos diferenciados -piénsese, por ejemplo, en las escenas de los pordioseros con que inicia el relato, las tajantes distinciones entre unos mendigos y los demás mendigos en el pórtico de la iglesia-, Zambrano va a coincidir parcialmente con Unamuno, pues para ella, según lo indica en el ensayo de 1938, el novelista armó un retrato de un "mundo anárquico", es decir, en crisis y sin un sistema que lo moldee. En sus dos largos textos acerca de la novela, la filósofa, por cierto, parecerá no interesarse tanto por un sistema social complejamente constituido, como sí lo hará, en cambio, principalmente por la forma en que Benigna se destacará entre todos los hombres y las mujeres de su entorno inmediato: Madrid y sus alrededores, la periferia de la corte y de la villa. La apreciación de Unamuno acerca de una "muchedumbre" se opone, sin embargo, a ese orden que se refleja muy bien en las páginas 
de Misericordia, el cual nos servirá para encontrar allí representados prácticamente todos los estamentos sociales del Madrid del momento histórico recreado por Pérez Galdós -desde los limosneros hasta el muy rico pariente de doña Paca, sin faltar, por supuesto, las clases medias en su amplia diversidad. Zambrano sobre todo pondrá en relieve a Benigna y a los hombres y mujeres hacia los que fluctúe su graciosa misericordia; esta preferencia ejemplificaría uno de los propósitos de la novela galdosiana y se vincularía así mismo, curiosamente, con un asunto destacado por Unamuno: retratar por medio de las construcciones novelísticas esas criaturas que de otro modo habrían sido arrastradas por las "aguas amenazadoras" de la historia general. Benigna es en ese sentido un alto y singular ejemplo de lo intrahistórico, un verdadero hallazgo.

Es imposible dejar de advertir en el ensayo de 1938, además, la forma en que Zambrano describe el que, según su punto de vista, sería el problema mayúsculo del pueblo español, problema que a su vez pareciera resurgir y rebrotar en el contexto de la Guerra Civil de 1936, asunto escabroso que tendrá que ver con la presentación no sólo de una "muchedumbre", sino de una sociedad verdadera: "Porque de todos los problemas que a un español le acongojan, ninguno más grave que este de la cohesión, de la unidad del pueblo español. Ninguno más empapado de sangre y en sales de amargura" (2014, p. 576). Esta observación quizás explique, en gran medida, el interés que en ella generó la obra de Galdós por aquellos años belicosos y, en particular, la novela sobre la que escribió muchas páginas. Años más tarde, regresaría Zambrano a esa imagen, Nina en medio de una comunidad sin forma: "Rodeada de la muchedumbre de los personajes, sola sin soledad. Más que sola, impar, única" (2014a [1960], p. 540). En su concepción del mundo novelístico galdosiano, Misericordia ocupará el sitio central en la producción de Galdós; y Nina, ese personaje solitario sin soledad, a su vez, va a ser el corazón de la novela, su centro indispensable.

Valdrá la pena anotar aquí una idea que Zambrano insertó al principio del texto de Hora de España y que tendrá que ver con la funcionalidad general que ella atribuye a la obra del canario: presentar al lector las "entrañas al descubierto" de su patria. La España que retrata y reconstruye Galdós, según Zambrano, y me parece que la frase es elocuente, es la del "harapo y la locura", la de un país que sufre entonces una crisis económica, pero tam- 
bién una crisis psicológica o espiritual, una nación que no ha logrado asimilar el pasado histórico, que se inserta en el ámbito de la decadencia y que presenta, como consecuencia de ello, "el amasado revoltijo de clases sociales a las que la miseria ha puesto al igualitario nivel del arroyo" (2014 [1938], p. 579).

Antes ya revisamos cómo Zambrano parecía coincidir con Unamuno en esa visión de la muchedumbre -o de ese mundo anárquico decimonónico- en las páginas de las novelas galdosianas. Zambrano, sin embargo, encuentra que Misericordia cumpliría con una función especial, con una función, digamos, unificadora de ese orden social, de esa España invertebrada a la que faltaba, según José Ortega y Gasset, convertirse en una "comunidad de propósitos" para asegurar su existencia. Esto se explica, quizás, desde el contexto histórico en que Zambrano lee e interpreta esta novela central, un momento de inequiparable inquietud a causa de los acontecimientos bélicos de la Guerra Civil:

Si Fortunata nos ofrece el misterio en que un ser humano individual aparece ligado, identificado en cósmica unión con la especie toda, y, aun más allá de ella, con la naturaleza -misterio de la maternidad imponiendo su ley-, Misericordia nos muestra otro misterio, el de la fuerza de cohesión de un pueblo más allá de la locura y de la prudencia, sacando su fuerza de su prodigalidad, su esplendor de la miseria. Misericordia es la razón de la sinrazón de España, el orden en el disparate y la locura, y en este sentido -razón de la sinrazón, hecha patente- está más allá del libro genial y profético de nuestro pueblo, en la misma línea y más allá del mismo Don Quijote (p. 574).

Las palabras de Zambrano son en esta ocasión transparentes: Misericordia superaría el estatuto de un texto literario común y corriente y se habría convertido en un fenómeno que amalgamaría, gracias al lúcido contenido de sus páginas, a todos los españoles, no únicamente a aquellos de la época presente o contemporánea, sino también a los de la España decimonónica y todavía más lejos; en este sentido, se explica la presencia de un personaje casi medieval como Almudena, el cual parece recuperado del contexto histórico y cultural perteneciente a la España antigua, de ese mundo en que supieron convivir cristianos, judíos y moros. Para Zambrano, todas las novelas de Galdós habrían reflejado a España en su "trágica dualidad", 
que, para la filósofa, era el resultado de una fallida asimilación del pasado histórico; el estallido de la Guerra Civil confirmaría, precisamente, la intuición. Misericordia sería el libro que habría podido curar ese divorcio, esa sempiterna actitud cainita, e incluso superar las posibilidades que habría tenido el texto del Quijote en esa misma función reconciliadora o unificadora. Es conocida, por lo demás, la intención que Unamuno llegó a atribuir en su Vida de don Quijote y Sancho (1905) a la principal obra cervantina: el escritor vasco leyó el libro no como una novela, sino como una suerte de evangelio español. $\mathrm{Si}$ para Ortega y Unamuno la obra máxima de Miguel de Cervantes era el libro al que se debía de acudir para entender y resolver el conflicto español, Zambrano propone algo vastamente discrepante: un texto decimonónico; esto, según creo, es un fuerte replanteamiento y una corrección de aquello estipulado por sus dos grandes maestros (Unamuno y Ortega). La filósofa encuentra en esta especialísima novela de Galdós una medicina o un remedio para el hombre de su patria. En este sentido, el texto de Pérez Galdós cumpliría con una misión semejante a la que Zambrano confirió en otros textos a Séneca -el filósofo estoico por excelencia- como "curandero" del alma; pero en este caso su sabiduría no salvaría la salud de un individuo, sino de la nación entera:

A medida que penetramos en el mundo de Misericordia, sentimos que nos vamos sumergiendo en nosotros mismos atravesando diversas capas; la más inmediata, la social: aquella en que nuestro ser individual convive mezclado con los de la misma clase social o grupo. Y más profundamente, y con tanta fuerza que obra esta primera, está la otra zona de convivencia con el pueblo todo: la dimensión en que somos hijos de España, en que corremos su suerte, en que nos desgarran sus heridas, nos aminoran sus decadencias y nos sustenta su esperanza. Es la zona de nuestro ser en que somos simplemente españoles (p. 575).

La lectura individual del texto de Galdós podría otorgar al lector potencial -que sería parte de una comunidad- una experiencia que rebasaría el mero entretenimiento o placer hedonista de la lectura: incorporaría a quien lo leyera en su propia realidad histórica y social, una realidad que, si bien se compartiría con los hombres y mujeres de la misma clase o estamento, sumaría también, de este modo amplio, al pueblo entero con 
todos sus estratos y capas. Esto último permitirá al lector reconocerse a sí mismo entonces como parte de una entidad que acepta la presencia de lo heterogéneo en un solo territorio, de un pueblo con una misma historia y con un momento presente compartido. El lector de Misericordia, siguiendo la propuesta de Zambrano, se sumergiría en el libro y saldría transformado: se reconocería como un español más con una sola historia.

En "Nuestra impresión de Galdós" (1920), Unamuno por lo menos reconocerá este otro elemento adicional en la obra del canario:

Si la obra de un artista, y un artista y no otra cosa ha sido Galdós -no un pensador, no un crítico siquiera-, consiste en expresar la vida que en torno de él se desenvuelve, Galdós ha cumplido su obra. Ahora que esa vida nos resulta mortecina y crepuscular y tediosa. Ninguna fuerte pasión ni acción la sacude (1966a, t. 3, p. 1208).

Zambrano sabrá distinguir, por su parte, precisamente lo contrario: ese esfuerzo descomunal por captar en la novela, desde la pasión creadora, la vida; incluso, Benigna terminará por convertirse en el símbolo máximo de una vida vivida, no pensada, no racional, sino puramente vital. Los textos de Unamuno son breves artículos periodísticos, acaso cargados con una reconocible e indomable sinceridad; por ello mismo, mucho nos dicen acerca de la forma en que el autor de La tía Tula concebía genuinamente la obra galdosiana en un período de reconocida madurez intelectual y literaria y de gran fama pública. Como sugerí antes, el concepto de intrahistoria se habría convertido en una noción que llegó a influir en el pensamiento de Zambrano y que pudo haberla guiado al momento de ir desarrollando su análisis, sobre todo en el texto inicial de 1938. Veamos cómo esto se despliega en la siguiente observación suya:

De este remolino ensangrentado que es la vida española del siglo xIx, lo que Galdós nos da es la vida misma, la sangre misma. La vida del español anónimo, de oscuro nombre genérico, apegada a un pueblo, a una comarca, a un trozo de tierra en fin, con sus viñedos y garbanzales, con sus trigales y roquedas, o a una ciudad plantada en el desierto, como Madrid, rodeada de vertederos y escombreras, de tétricas estaciones de ferrocarril. Vidas que lo son, tanto de un ser humano, como de un pedazo de suelo, de linajes y tradiciones; vidas anónimas con sus infinitas raíces en el 
ayer: tejido tramado con todos los elementos de nuestro ser de españoles (2014, p. 569).

Por supuesto, la filósofa no seguirá puntillosamente a don Miguel de Unamuno en sus concepciones, pero sí se planteará esa dialéctica entre el hombre y el devenir histórico en que éste se encuentre atrapado, entre el hombre y la historia general que le tocará vivir desde su papel anónimo. En las palabras prologales de La España de Galdós (1960), Zambrano incluyó una idea que se convierte en una actualización o revaloración del concepto de la intrahistoria:

Existe algo más que ha permitido inclusive al ser humano que le sean visibles la condición trágica y la condición novelesca de su vida, de su propia vida, lo que hace que la vida humana sea trascendente de por sí. Mas tampoco al hombre le basta. Porque el hombre es el ser que padece su propia trascendencia. La padece actualizándola, extrayéndola de la ambigüedad y aun de la realidad, en un activo padecer. Lo que hace del hombre criatura de experiencia y no solo de historia: de verdad y no sólo de realidad (2014b, p. 521).

El análisis que Zambrano haga de la obra de Galdós la llevará hacia los caminos de la esperanza y de la trascendencia. El hombre, como sujeto histórico, como ser individual, es incorporado en ese sueño (o en esa pesadilla) que es precisamente la historia; y a pesar de su minúscula realidad podrá pisar los territorios de lo trascendente, como Zambrano lo plantea aquí por ejemplo: "Algo inasible, una insignificante historia, un inexistente personaje, dotado de una extraña vida; un mínimo soporte «material», de sustancia o argumento novelesco, del que escapa. Una vida que parece estar al borde de no necesitar ya casi nada de lo que toda vida necesita aquí, en el lugar que de la vida conocemos" (p. 525). Una novela como Misericordia, por lo demás, pareciera consumar aquella idea que planteó Unamuno en las páginas de Cómo se hace una novela: la exigencia de que todo hombre llevase en su fuero interno no su propia vida, sino sobre todo su propia ficción (esto ocurre no con Nina, pero sí, por ejemplo, con el personaje de doña Paca). Considérese esta otra idea unamuniana que serviría espléndidamente para ejemplificar lo que Zambrano, de forma inevitable, sí detecta en Misericordia: 
No fue la restauración de 1875 lo que reanudó la historia de España; fueron los millones de hombres que siguieron haciendo lo mismo que antes, aquellos millones para los cuales fue el mismo sol después que el de antes del 29 de septiembre de 1868, las mismas sus labores, los mismos los cantares con que siguieron el surco de la arada. Y no reanudaron en realidad nada, porque nada se había roto (1996 [1902], p. 63).

Será Benigna una de esas mujeres que se dedicaron, precisamente, a sus mismas labores, sin cambiar el rumbo suyo a pesar de la atroz ruina económica; y que al hacerlo, terminaron por abrigar y sostener la sociedad de su época. De hecho, Nina terminará por cargar a muchos hombres y a muchas mujeres sobre su muy "frágil espalda"; de sus actos dependerá la supervivencia de toda una galería de personajes típicos, criaturas que reflejan las enormes limitaciones de la segunda mitad del siglo XIX.

Para terminar este breve cotejo entre las ideas de Unamuno y las de Zambrano en torno a la obra de Pérez Galdós, creo que valdría la pena leer un pasaje de un libro que la filósofa no publicó en vida junto con los otros textos dedicados a la figura de Miguel de Unamuno, pero cuyo interés es, sin duda, mayúsculo. Me refiero a los textos reunidos por la investigadora Mercedes Gómez Blesa:

...para explicarse a Unamuno, basta con leer las novelas del otro español genial -genial en su indiferencia de espejo- que le precedió en una generación, que es Galdós. De Galdós a Unamuno hay un verdadero abismo tan pronunciado que, al enfrentarlos, Galdós retrocede y se adentra en el tiempo haciéndose más viejo, y Unamuno avanza hasta hacerse coetáneo nuestro, contemporáneo de nuestra edad, mientras que Galdós, cada día más visible en su genialidad, aparece como alguien de una época anterior, inmediata a la nuestra, pero que no es la nuestra. Galdós es el mundo del que hemos salido, el que dejamos a nuestra espalda. Unamuno es de nuestro tiempo (Zambrano 2015c [1943], p. 53).

La observación es interesante porque plantea, por medio de la utilización y del recuerdo de estos dos escritores representativos, la consideración de dos épocas radicalmente distintas: se convierten los escritores así en símbolos de dos temporalidades. Es necesario observar que en la cita Zambrano no habla de libros, de obras específicas, sino de autores cabales. Antes vimos la propuesta consistente en convertir a Misericordia en un 
texto que habría representado literariamente el drama de España y, acaso, su solución desde una lectura guiada por la "razón poética”. En el texto ahora citado, Zambrano no nos explica las razones por las que Unamuno estaría más cerca del mundo contemporáneo más allá de una cronología; pero podemos pensar que se debe a que el mundo de la Restauración, y de las preocupaciones decimonónicas, quedaría ya muy lejos. Las aparentes preocupaciones existencialistas de Unamuno se acercarían mucho más, sin duda, a las inquietudes del hombre contemporáneo. Hay, sin embargo, un fuerte punto de contacto entre ambos autores que la filósofa sí reconoció: El amigo Manso (1882) de Galdós, texto que parecería prefigurar la nivola unamuniana. Hay un puente que une las obras de dos autores, en apariencia, distintos; y que sin embargo compartieron -desde dos épocas separadas- preocupaciones semejantes: descifrar la realidad desde lo propiamente literario, desde la ficción y su constante ambigüedad.

\section{MÁS dí́logos INCOMPletos: OrTEga y GASSET}

Es curioso observar que otro autor con quien constantemente dialoga la obra de María Zambrano, José Ortega y Gasset, prácticamente nada dejó escrito acerca de la novela de Benito Pérez Galdós (véase Morón Arroyo 1966). En la recopilación general de sus escritos, en sus obras completas, apenas si aparecerá mencionado en un par de ocasiones el novelista canario; y cuando Ortega utilice los nombres representativos de los escritores de la pasada centuria para ilustrar algún argumento, lo omitirá por el escaso o nulo interés que le suscitaba su obra, tan cercana a la estética del siglo xix y, por supuesto, al realismo. En el póstumo libro Origen y epílogo de la filosofía, Ortega dejó anotada una idea que nos puede servir para orientar las siguientes páginas y que podría justificar algunos de los silencios y de las omisiones en sus ensayos de crítica literaria: "Todo texto es fragmento de un contexto inexpreso" (1977, p. 67). Lo que nos ha de interesar a continuación será, precisamente, lo "inexpreso"; y cómo María Zambrano ha de comunicar y articular esos grandes silencios en torno a la figura de Pérez Galdós, figura irremplazable del "contexto" hispánico. Como ha observado Ricardo Tejada (2011, p. 49), en modo muy sugerente, "La España de Galdós, de Zambrano, publicado en 1960, es uno de los pocos libros -por 
no decir, quizás, el único- en los que no aparece ninguna mención directa a Ortega. Algo significativo si tenemos en cuenta que es de los libros más profundamente unamunianos de su producción”. ¿A qué se deberá pues ese otro silencio?

De forma amplia, se reconoce el interés que llegó a manifestar Ortega por prácticamente todas las formas artísticas, sin olvidar, particularmente, el estudio de la novela; recuérdense las páginas que publicó acerca de la obra barojiana y las observaciones señeras en torno al Quijote, único libro realmente profundo para el filósofo dentro del ámbito milenario de la literatura española: "Para esos hombres era el Quijote una divina curiosidad: no era, como para nosotros, el problema de su destino" (2014, p. 89). La lectura que realizó Ortega de la obra de Cervantes en sus Meditaciones del Quijote (1914) es prácticamente cualquier cosa menos una aproximación filológica o erudita: es, más bien, una honda reflexión acerca de la figura del caballero andante y España, acerca de un método con que estudiar y pensar en la circunstancia particular del hombre y por tanto del arte. Es también, sin duda, un paso decisivo hacia la concepción de la razón vital. Será útil, para los efectos de este trabajo, recordar algunos pasajes de las Meditaciones, pues fue uno de los libros de Ortega a los que Zambrano siempre regresó en sus comentarios orteguianos.

Es impresión mía que hay en este influyente texto de Ortega algunas ideas que alcanzan a resonar fuertemente en $L a$ España de Galdós, aunque de modo indirecto, en sus vislumbres y en su método general a pesar de la distancia en el tiempo entre la publicación de los volúmenes respectivos y a pesar de las muchas diferencias y los propósitos divergentes de los autores. En el caso de Ortega y Gasset, será el Quijote, esa profunda obra literaria, una suerte de trampolín para el pensamiento suyo; Zambrano hará lo propio gracias a su capital lectura de Misericordia. En ambos casos, hay una preferencia por el texto novelístico como punto de partida para la reflexión amplia o por las "formas sacramentales" de las que habló Zambrano. Recuérdese, además, la noción que desarrolló la escritora: la idea de que los textos novelísticos habían cumplido la función, en España, de los tratados filosóficos, pues según ella "sucede que el pensamiento español, y sobre todo la metafísica española, anda dispersa en novela, poesía, cuentos y hasta refranes... que la encontramos en los lugares más insólitos y alejados del sistema, que anda errante y disuelta y de esta manera, sí, alcan- 
za lo que a los textos estrictamente filosóficos les falta: «vigencia»y «continuidad»" (2011 [1948], p. 84).

En sus Meditaciones del Quijote, por cierto, Ortega dirá algo que parcialmente nos ha de remitir a la frase antes citada, procedente de una de sus obras póstumas (Origen y epílogo...). Me refiero a una observación en torno a los procedimientos de la crítica y su naturaleza tal y como él los entendió (el "leer pensativo", según su propio término). Escribió Ortega en sus Meditaciones que él veía "en la crítica un fervoroso esfuerzo para potenciar la obra elegida" (2014 [1914], p. 38). Es necesario observar que inmediatamente después atacará las formas de la crítica literaria precedente, aquellas que, según el filósofo, iban de la obra al autor y finalmente terminaban con las anécdotas de la vida del artista sin profundizar más allá -recuérdese el muy duro señalamiento que hizo en contra de don Marcelino Menéndez Pelayo y en contra de don Juan Valera por sus supuestas incapacidades para obtener la "experiencia de lo profundo". Para mejor explicar su método crítico, Ortega nos remitirá al estudio que él dedica a la obra de Pío Baroja; lo que nos interesa de la siguiente cita será, sobre todo, la forma en que ésta concluye -la propuesta consistente en leer una obra literaria más allá de sí misma, para desbordar así los rígidos límites de su simple exégesis o del rígido comentario hermenéutico-:

Así, por un estudio crítico sobre Pío Baroja, entiendo el conjunto de puntos de vista desde los cuales sus libros adquieren una significación potenciada. No extrañe, pues, que se hable poco del autor y aun de los detalles de su producción; se trata parcialmente de reunir todo aquello que no está en él, pero que lo completa, de proporcionarle la atmósfera más saludable (p. 39).

Este camino -aquel que significará conceder a la obra su "atmósfera más saludable"-es precisamente el que recorre Zambrano al examinar Misericordia de Galdós. Veamos algunos ejemplos de esto, es decir, de ese tipo de lectura potenciadora de la obra literaria.

Podrá Zambrano, por ejemplo, determinar que el libro Misericordia ocuparía un lugar central en la producción del novelista, lo mismo que Nina en su calidad de personaje (un personaje que es además un centro); para la escritora, esto tendrá una gran relevancia, pues el centro, además de ser un sitio especial por razones casi topológicas, será también para ella un lugar 
abierto, un conducto que permitirá la comunicación -esto, claro, nos hace recordar un libro posterior suyo de 1977 en que la idea ha de resurgir y ha de explorarse con mayor detenimiento, detalle, alcance y brío: Claros del bosque. Otra idea de Zambrano que potenciaría la lectura de Misericordia-que le concedería su atmósfera más saludable- es aquella que le sirve para defender la noción de que este libro habría surgido sin una intención premeditada por parte del autor, sin un plan meticuloso, misteriosa y poéticamente, sin ser el resultado del mero artificio literario. En realidad, esto imposiblemente podrá defenderse más allá de la legítima intuición crítica de Zambrano: hay una convicción sin duda indemostrable.

Entre las aportaciones más deslumbrantes de la filósofa, hay que mencionar aquello que Zambrano sugiere cuando retome la figura del caballero cervantino. De entrada, la filósofa propondrá la ausencia absoluta de cualquier rastro de "novelería" en Misericordia; por ese camino, Zambrano intentará demostrar que el libro que hemos típicamente considerado y clasificado como una novela no lo sería del todo... Esta propuesta tendrá que vincularse con la noción de que Nina habría comenzado su camino donde -curiosamente- lo habría abandonado el famoso caballero creado por Miguel Cervantes en su novela. Si don Quijote convierte en novelesco todo cuanto mire y toque, influido, desde luego, por sus lecturas de los libros de caballería, y de toda la literatura que circulaba en la época, Nina se enfrentará en contra de un mundo real, caótico, en que los hombres y las mujeres sufren síntomas alarmantes: negar y renegar de la realidad sin poder acudir a la intercesión del texto literario como elemento mediador. Esto justificaría la idea de la ausencia, según Zambrano, de lo intrínsecamente novelesco en Misericordiay la función que tendría entonces su personaje principal o central, la criada: desnovelizar, ir en contra del discurso, según la filósofa, típicamente novelesco. En su interpretación, veremos que España entera se habría perdido en el mundo de la ficción, tal y como lo demostrarían los personajes fantasiosos, quijotescos, y desconectados de su realidad inmediata que habitan muchas de las páginas de Misericordia y muchas otras novelas de Galdós; por ejemplo, Isidora, protagonista de La desheredada.

De regreso a Ortega y sus Meditaciones, después de revisar estos ejemplos que potencian la lectura de Misericordia, creo que será importante revisar algunas de sus ideas en torno al realismo y su concepto. Según Ortega, para el hombre latino sería 
más importante la sensación y no el objeto en sí, la cosa en sí misma. Ése sería el elemento nodal del realismo que, a su vez, habría llegado a España para su desarrollo. Su concepción del arte realista se resumirá con estas palabras: "He aquí lo que llamamos realismo: traer las cosas a una distancia, ponerlas bajo una luz, inclinarlas de modo que se acentúe la vertiente de ellas que baja hacia la pura materialidad" (p. 126). Es decir, el realismo sería sobre todo una suerte de perspectiva impresionista; y no de camino para alcanzar el máximo conocimiento, como sí ocurre en cambio en el pensamiento de Zambrano:

El realismo... es una forma de conocimiento porque es una forma de tratar con las cosas, de estar ante el mundo, es una manera de mirar al mundo admirándose, sin pretender reducirle en nada. Tal es la manera de conducirse del enamorado. El realismo español no es otra cosa como conocimiento que un estar enamorado del mundo, prendido de él, sin poderse desligar, por tanto (2015b [1939], t. 1, p. 584).

En este contexto, es imposible dejar de traer a colación la siguiente cita, por lo que en ella nos dice Zambrano acerca del realismo y porque contiene algunas claves para profundizar en el método con que analiza La España de Galdós:

Alejada la vida española de estas raíces, el realismo español será, ante todo, un estilo de ver la vida, y en consecuencia, de vivirla; una manera de estar plantado en la existencia. No existe nada, ningún dogma, de este "realismo" que nos permita cómodamente situarlo, enfrentarnos con él y analizarlo. No; nunca las cosas españolas son tan cómodas. El realismo, nuestro realismo insobornable, piedra de toque de toda autenticidad española, no se condensa en ninguna fórmula, no es una teoría. Al revés; lo hemos visto surgir como "lo otro" que lo llamado teoría, como lo diferente e irreductible a sistema. Intentar sistematizarlo sería hacerle traición, sería suplantarlo por una yerta máscara; sería traer, en vez de la viva sustancia, su hueco molde. No hay fórmula, no hay sistema que compendie el realismo, nuestro arisco e indómito realismo, y nos permita traerlo como un cadáver a la sala de disección del pensamiento; nos hemos de contentar, si es que la fortuna nos ayuda, con evocarlo (p. 582).

Es claro que su idea del realismo desborda un modelo meramente teórico que sirviese para comprender una porción de la 
historia de la literatura o de la historia del arte. Por tanto, cuando nuestra filósofa lea Misericordia, novela sin duda realista, lo que ella buscará será aprehender el libro desde diversos frentes, pero nunca desde una sistematización, nunca desde una perspectiva teórica o dogmática que pudiese anular los significados más hondos de las desgracias y las desventuras padecidas por Benigna y por sus compañeros en la novela; en todo caso, será la razón poética la brújula permanente de su pensar. Veamos ahora la forma en que Ortega y Gasset usa el mismo concepto en su comentario del Quijote, se notará también un uso personal del término: “¿Ocurre esto en Cervantes? ¿No es, acaso, lo que quiere indicar cuando se le llama realista, su retención dentro de las puras impresiones y su apartamiento de toda fórmula general e ideológica? ¿No es, tal vez, esto el don supremo de Cervantes?" (2014 [1914], p. 90). Lo que podría pensarse en una primera instancia -el realismo como un producto renovador del arte mimético- es renegado en el apunte: el hidalgo manchego logra no sólo combatir en contra de los imaginarios molinos de viento, sino también en contra de esa "fórmula general e ideológica" que buscaría apresarlo. Consecuentemente, Ortega verá en don Quijote no sólo un personaje, sino también una presencia que trascenderá su calidad de simple creatura literaria: "la larga figura de Don Quijote se encorva como un signo de interrogación; y es como un guardián del secreto español, del equívoco de la cultura española" (p. 89). Benigna de Casio, en el análisis propuesto por Zambrano en La España de Galdós, también terminará por convertirse en algo más que una simple mujer del pueblo: será un símbolo de los valores humanos, de su enaltecimiento, de una misericordia que terminará por unificar a los hombres y las mujeres de la sociedad. Si don Quijote es un acuciante signo de interrogación, Benigna, por momentos, parece ser, en el análisis de Zambrano, la respuesta práctica y tangible, frente al drama humano y español, a su tragedia. De allí la importancia enorme que adquirirá en las páginas que Zambrano dedique a Galdós y, particularmente, al comentario de Misericordia. Es posible observar que el análisis de la filósofa parte de la consideración de un personaje-Nina- en que podrá hallar elementos que faltarían, y que no estarían presentes, en el personaje de don Quijote.

Antes de terminar con esta parte de la discusión, valdría mucho la pena apuntar algunas ideas acerca de la diversa forma en que ambos escritores (Ortega y Zambrano) encararon 
el siglo XIX por tratarse de la época retratada en Misericordia. Recordemos, por ejemplo, lo que apuntó Ortega también en sus Meditaciones en relación con el momento histórico recreado literariamente en muchas de las novelas galdosianas: "La Restauración significa la detención de la vida nacional. No había habido en los españoles durante los primeros cincuenta años del siglo xix complejidad, reflexión, plenitud de intelecto, pero había habido coraje, esfuerzo, dinamismo" (p. 35). En Vieja y nueva política (1914), el filósofo observará que la época de la Restauración terminó por convertirse en un "panorama de fantasmas" (p. 35). Y también observemos este otro apunte perteneciente a su España invertebrada (1921) en que lamenta la inexistencia de figuras de primer orden durante el mediocre período de la Regencia: "Restauración y Regencia no sólo transcurrieron exentas de tamañas figuras, sino que representan la hora de mayor declinación en los destinos étnicos de España. Nadie puede dudar de que el contenido vital de nuestro pueblo es hoy muy superior al de aquel tiempo" (2007, p. 83). La visión general que Ortega adquirió del siglo xix fue, como queda dicho, nada optimista. La literatura decimonónica estaba, según él, necesariamente condenada al fracaso y a su abandono próximo, puesto que habría de volverse pronto ilegible por carecer de "la menor cantidad de dinamismo poético".

Si partimos de la noción de que la lectura que haga Zambrano de la novela Misericordia será siguiendo el camino de la razón poética, el juicio de Ortega entonces quedaría -de algún modo-corregido e incluso superado por ella. Zambrano encontrará en el personaje de Benigna una construcción netamente poética -cosa semejante ocurrirá, por lo demás, con su análisis de Fortunata en el libro correspondiente, alma gemela, según Zambrano, de don Quijote, y símbolo indispensable de la fecundidad. Es también notable el hecho de que Zambrano haya creído entonces encontrar en todos los hombres y mujeres decimonónicos verdaderos personajes de novela: "Personajes de novela son todos los españoles del siglo xıx. Galdós, innumerablemente, nos los muestra, y la ausencia del Romanticismo es tan patente en la España que sus páginas maravillosas nos reflejan, como la falta de Reforma en Cervantes" (2015 [1937], t. 1, p. 218). Zambrano concibió el siglo XIX en España, sin embargo, como una época condicionada por una suerte de desgano secular y heredero de una crisis en que la nación española se jugaba su existencia. Creo que valdrá mucho la pena observar, 
en este ejercicio de contrastes que hemos venido desarrollando, el severo enjuiciamiento de la tradición que planteará Ortega en contraposición con la mirada tolerante y comprensiva de Zambrano, mirada que se posa de forma benevolente en la tradición decimonónica y en la figura de don Benito Pérez Galdós:

¡La tradición! La realidad tradicional en España ha consistido precisamente en el aniquilamiento progresivo de la posibilidad de España. No, no podemos seguir la tradición. Español significa para mí una altísima promesa que sólo en casos de extrema rareza ha sido cumplida. No, no podemos seguir la tradición; todo lo contrario: tenemos que ir contra la tradición, más allá de la tradición. De entre los escombros tradicionales, nos urge salvar la primaria substancia de la raza, el módulo hispánico, aquel simple temblor español ante el caos (Ortega y Gasset 2014 [1914], p. 93).

Este mundo de lo novelesco en el que se ha refugiado la vida española es recogido con perseverancia inigualable por un genio de la paciencia y la humildad, inclinado en devoción sobre la vida vulgar, don Benito Pérez Galdós. El mundo que con tanta realidad nos presenta es el mundo de la tradición, de la que queda. En él aparece a través del delirio y el disparate, para nuestro consuelo, la única continuidad de la vida española. La unidad verdadera de España. Aparece en toda su obra dispersa, inagotable, pero de modo más concentrado y significativo en dos gigantescas figuras de mujer que encarnan las dos fuerzas cohesivas y creadoras a las que nada ha podido abatir: la fecundidad y la misericordia (Zambrano 2015b [1939], t. 1, p. 650).

Es cierto que ambas citas pertenecen a momentos históricos distintos y que por ello su cotejo resulta cuestionable; sin embargo, pienso que este ejercicio comparativo tendrá su interés en la medida en que las impresiones de los escritores resultan dispares. El fragmento recogido de las Meditaciones del Quijote se correspondería con el instante en que Ortega escribió su primer libro; y la cita de Zambrano pertenece al exilio en México. En relación con el fragmento orteguiano, es notable la vehemencia con que el filósofo dictamina que la tradición es una suerte de lastre que debería ser abandonado; especialmente, en el caso de España. Al hablar de la tradición española, Ortega exige no aceptar todos los productos españoles, todas sus manifestaciones culturales. La tradición, en su calidad de promesa, no ha traído lo que se esperaba de ella; y, por tanto, debe- 
ría renunciarse a esa esperanza, según Ortega, de rescatar así "la primera substancia de la raza". Años después, Zambrano, en cambio, enaltece en su análisis de Misericordia el legítimo papel ejercido por la tradición. Lo que se rescata en las páginas de la novela, lo que se representa, no es sólo esa "vida vulgar" a la que pertenecen los personajes, sino también el "mundo de la tradición" en que éstos, sin duda, cómodamente se insertan. Ese "delirio" y ese "disparate" son los engranes que permiten dar continuidad a la vida española; $y$, particularmente, Benigna de Casio y Fortunata son instrumentales para tal cumplimiento. Para Zambrano, la tradición española es esa corriente que se ha movido secretamente por canales ocultos; y que va dejando, sin embargo, su huella definitiva en la vida española.

Para cerrar este apartado, quisiera recuperar una imagen que sirvió a Zambrano para sorprendentemente filiar la figura de Ortega y Gasset con la de Benito Pérez Galdós. Para ello, es necesario comentar brevemente el contenido de un artículo suyo escrito en Roma: "Un frustrado pliego de cordel de Ortega y Gasset", aparecido en Papeles de Son Armadans en el año de 1963. En dicho artículo, Zambrano recuerda al Ortega que ella trató durante los años de 1933 y 1934 -y del que en su momento fue "discípula bastante heterodoxa", como bien ha observado Mercedes Gómez Blesa (2004), quien dibuja de forma muy precisa los encuentros y desencuentros entre ambos filósofos. En aquella época, según lo consigna Zambrano, no estaba Ortega ejerciendo el periodismo, profesión que, como se sabe, era consustancial a su vocación de escritor. El maestro reveló a su discípula un proyecto secreto que resultaba muy delicado: la publicación sorpresiva de un "pliego de cordel" que contendría un artículo suyo. En el ensayo, Zambrano intencionalmente omite el tema de ese texto inexistente, pero se deja entrever que habría tenido un carácter político o social por algunos indicios. Por ejemplo, el recuerdo que describe allí Zambrano de su profesor: Ortega recorriendo las calles de Madrid, algunos barrios matritenses que él normalmente no visitaba, con la intención de "tomar el pulso" de la vida del pueblo español. Esto hace que Zambrano escriba casi treinta años después:

Andaba así, extravagando ensimismado, recogiéndose dentro de sí mismo, en ese lugar donde se oye la realidad y no sólo se la ve, como un novelista. Por entonces, yo había descubierto a Galdós bastante sola en ello y aun a contracorriente, y había sabido que 
don Benito se asomaba al balcón de su casa y allí permanecía mucho rato antes de ponerse a escribir (2011a [1963], p. 171).

En el pasaje, se destaca ese descubrimiento hecho "a contracorriente", desde luego, por la controvertida fama con que corrían por entonces los volúmenes del canario. Es curioso cómo la filósofa vinculará el trabajo de su profesor con el del novelista gracias a dos elementos: sus lecturas juveniles de Galdós y la preocupación anticipatoria orteguiana. Ortega, según la cita, habría compartido con el creador de obras ficticias la voluntad de observar el mundo y sus habitantes.

Finalmente, para complementar todo lo anterior, valdrá la pena copiar en seguida el pasaje de un artículo incluido en Las palabras del regreso en que Zambrano imagina a Pérez Galdós instalado en ese balcón desde el que vio y oyó a España:

He sabido que pasaba horas enteras en el balcón, asomado, oyendo el murmullo de la muchedumbre, sin discernir ninguna palabra, es decir, asomándose no al abismo del océano, pero sí a un abismo pacificado. Y su obra literaria queda marcada por la inmensidad del océano y por lo irresistible de ese silencio, un tanto amorfo, de donde van surgiendo como por sí mismos los grandes personajes, que no son siempre los que aparecen en primer término (2009 [1986], p. 200).

Ese mar del que habla es el mismo océano en que se habría sumergido su maestro José Ortega y Gasset durante sus paseos por las calles matritenses algunos pocos años antes del estallido de la Guerra Civil.

\section{MÁs VALORACIONES GALDOSIANAS}

Mientras Ramón Pérez de Ayala (1919 [1916]) -autor perteneciente a la Generación del 14- consideraba que "Cervantes y Galdós como dos altas montañas, fronteras y mellizas, están separadas por un hueco de tres siglos" (p. 53), uno de los amigos de Zambrano, José Bergamín, veía en el canario "la gran escombrera nacional" en un duro artículo periodístico de 1933 ("Galdós, redimuerto") -no deja de ser llamativa la metaforización contrastante: montaña vs. escombrera. Diez años antes, en 1923, Antonio Espina señalaba que a la obra de Galdós le había 
faltado "sentido crítico, o, con más exactitud, autocrítico". Para Espina (1923), era Galdós "una enorme medianía” y también "un novelista para la clase media" (p. 114). A diferencia de María Zambrano, quien sí encontró en las páginas de Misericordia un hondo texto que debía leerse, y leerse desde la razón poética, como un libro en que se resolvían cuestiones nodales del hombre y de España, como una guía, Espina niega cualquier rasgo de profundidad en las novelas de don Benito:

Cuando quiso dibujar caracteres extremos lo hizo en línea recta, despegándolos del suelo y rodeándolos de falsa atmósfera pseudofilosófica o histórica, Centeno, Nela, Ángel Guerra, Benigna, Cordero, Doña Perfecta -anotemos de paso la pueril manía del simbolismo nominativo- son gente de armadura espiritual. Caracteres de "una pieza", como se decía antes, cuya misión, más que vivir por cuenta propia, parece ser la de representar el papel que previamente les ha asignado el novelista (p. 116).

Es cierto que también podríamos encontrar textos que terminarán por convertirse en encomios igualmente desmedidos, como los publicados por Salvador de Madariaga y Federico de Onís ${ }^{4}$. Quizás resulte aquí más interesante, y como una suerte de anticipación de lo que llegaría a ser La España de Galdós -libro que se fue escribiendo a lo largo de diversas décadas, pero con un aliento único-, recordar la preocupación de Luis Cernuda por los verdaderos e inexistentes lectores de la obra del escritor canario. En su ensayo "Galdós" de 1954, el sevillano pondera el hecho de que hayan transcurrido muchas décadas desde la muerte del autor y que todavía no haya aparecido un conjunto de lectores que pudiesen realmente valorar y entender su obra, con la advertencia agregada de que quizás nunca llegasen finalmente por aparecer, es decir, que esos lectores ideales pudieran algún día conocer esa obra mal comprendida, sobre todo, por los críticos académicos. Es por cierto el mismo temor que el poeta sintió en relación con su obra poética: que no llegase a ser valorada por la falta de un público con

${ }^{4}$ Salvador de Madariaga (1924, p. 67): "En nuestros días Galdós ha gustado el vino de la gloria -de que gozaba con su casi infantil apetencia de todo placer-y se ha visto aclamado por sus contemporáneos como el genio literario más grande que España ha producido desde el Siglo de Oro". Por su parte, el texto que Federico de Onís (1932, p. 114) dedica a Pérez Galdós es para su autor un homenaje "del más grande de los españoles modernos". 
las cualidades óptimas para ello. Acerca de una de las pretendidas deficiencias de la obra galdosiana, dirá Cernuda:

Se ha repetido que Galdós no sabe escribir, que no tiene "estilo". No sé qué llamarán estilo quienes tal cosa dicen. Galdós creó para sus personajes un lenguaje que no tiene precedentes en nuestra literatura, ni parece que nadie haya intentado continuarlo o podido continuarlo. Cada personaje de sus novelas nos habla por sí mismo; es un lenguaje directo y revelador, familiar y sutil a un tiempo (1994 [1954], t. 2, p. 520) .

Zambrano no se detiene a estudiar, en realidad, el estilo literario de don Benito - de hecho, ya vimos cómo el realismo no es para ella ni siquiera propiamente un estilo, sino una rica forma de conocimiento-; su manera de leer y comprender Misericordia, por ejemplo, va más allá de la contemplación de los usos verbales específicos con que los personajes se configuran, del examen de su lenguaje. En todo caso, la legitimación que la filósofa hará del texto galdosiano tendrá que ver con la decodificación simbólica del texto novelístico.

Hay que decir, todavía acerca de la problemática valoración del estilo galdosiano, que hacia finales de los años sesenta, un contemporáneo de Zambrano, el escritor y crítico Guillermo de Torre, aún estaba inmerso en la discusión en torno a las supuestas deficiencias del estilo galdosiano: "Es cierto que Galdós abusa muchas veces del lenguaje mostrenco que llena excesivamente su prosa narrativa con modismos locales o de época, de dichos superfamiliares, escribiendo como en mangas de camisa" (1969, p. 207). El investigador, y gran conocedor de las vanguardias artísticas europeas, justificará el supuestamente poco sublime estilo galdosiano argumentando que el novelista habría tenido demasiadas cosas que contar y muy poco tiempo para considerar luego cómo contarlas... En el mismo

${ }^{5}$ Resulta imposible dejar de recordar aquí el poema que dedica CERNUDA a Galdós en su último libro: Desolación de la Quimera (1962). En la segunda parte del "Díptico español", en un poema que lleva por título el de "Bien está que fuera tu tierra", Cernuda rememora su encuentro infantil con los libros de Galdós y su consecuente amor por la literatura. Durante los años del exilio, el escritor canario se convertirá en un símbolo de la patria perdida, pero en su vertiente más hospitalaria, generosa, liberal y noble: "La real para ti no es esa España obscena y deprimente / En la que regentea hoy la canalla, / Sino esta España viva y siempre noble / Que Galdós en sus libros ha creado. / De aquélla nos consuela y cura ésta" (1999, wv. 167-171). 
texto, Guillermo de Torre advertirá: "Sus novelas son expresiones esencialmente artísticas, condicionadas por la época, cierto es, pero cuya trascendencia no ha de encontrarse fuera de ellas mismas" (p. 216). La concepción que guía el análisis de Zambrano va en sentido contrario: ella encontrará siempre en las novelas de Galdós, más allá del discurso de los personajes, y de la trama en que el novelista los coloque, un significado trascendente, el cual desbordará muchas veces, incluso, las intenciones conscientes y primeras del autor (ese afán potenciador que aprendió probablemente gracias a sus lecturas orteguianas). En este sentido, Ana Bundgård (2000) ha sugerido certeramente que Zambrano leyó e interpretó los textos galdosianos desde un enfoque enteramente personal. Bundgård señala que existe una suerte de proyección de la autora en la novela, en cuanto que se erige como "escritora-intérprete" del texto.

$\mathrm{Al}$ comentar brevemente los puntos de contacto y las diferencias entre los escritores de la época y Zambrano, conscientemente hemos postergado hasta ahora el nombre de Rosa Chacel. Hay un dato que emparenta la lectura que Chacel hizo de Galdós con aquella otra que hizo Zambrano: el hecho altamente significativo de que ambas escritoras hayan realizado sendas publicaciones en la revista Hora de España durante los años aciagos de la Guerra Civil y con el mismo tema. El texto de Zambrano de 1938 posee una complejidad mayor que el de Chacel, pero no por ello deja de ser muy interesante la nota preparada por la novelista. En los dos casos, las autoras recurren a Galdós con la intención de acaso iluminar o entender los hechos del difícil momento histórico que atravesaba España. Chacel confiere a su texto un carácter mucho más políticamente explícito y menos sociológico y filosófico. De hecho, en la introducción se dedicará largamente a explicar la naturaleza de la revolución desde una perspectiva, podríamos decir, metafórica: por medio de la imagen del agua que empieza a agitarse y a revolverse. Zambrano, por su parte, en una ocasión conjugará la figura de Galdós con el programa revolucionario; el artículo que dedicó al estudio de la poesía de Arturo Serrano Plaja cierra con una muy curiosa explicación en torno a la puntualización de cómo sería una revolución con carácter español: "Una revolución que ha dado un paso para acercarse a eso que nuestro Galdós nombrara, con la inconsciencia de la profecía, «materialismo de la misericordia»" (2015 [1937], t. 1, p. 274). 
Después de una larga introducción, Chacel incluirá una idea que pareciera alimentar la noción de que en las etapas críticas -y quizás esto haya sido también el elemento que empujó a Zambrano a escribir acerca de la obra de Pérez Galdós en aquel momento- resulta necesario beber de las aguas de la tradición: "Cada pueblo y cada hombre debe escarbar en su propio tesoro hasta encontrar el oro puro que para muchos no será más que una palabra, acaso un nombre" (1977 [1937], t. 1, p. 128). Ese tesoro será, precisamente, Benito Pérez Galdós. Chacel escribe el artículo, según indica, para "hacer resonar un nombre": el del novelista canario. Acaso se deba a la preferencia política que el escritor siguió a lo largo de su vida: una posición liberal, concepto que se omite explícitamente, por cierto, en el texto. De este modo, Chacel podrá recomendar lo siguiente: "El que quiera cobrar alientos en la lucha actual, el que necesite sentir en el corazón germinar una firmeza, altivamente espontánea, sustancialmente propia, hunda su pensamiento en las páginas galdosianas, láncese a atravesar esa extensión, que es, al mismo tiempo y en cada uno de sus puntos, selva y páramo" $(i d$.$) .$ Es notable la recomendación si consideramos el asedio brutal que sufrió la República en ese momento. Es decir, ¿qué consuelo inmediato podría sacar, por ejemplo, un miliciano al colocar en su pensamiento la figura y la obra de Pérez Galdós? En todo caso, la recomendación incluye, sobre todo, leer o recordar los volúmenes de los Episodios nacionales, obras que, por cierto, no interesaron tanto a Zambrano -esto es verdadero si pensamos, en cambio, en su predilección por las novelas contemporáneas y, particularmente, por Misericordia, libro que para ella será legítimo centro de la obra galdosiana. Chacel cerrará su artículo con un llamado enfático a recobrar y revalorar la figura de don Benito Pérez Galdós: "Todo el que quiera recordar y esperar, todo el que quiera sustentar su confianza en el cimiento inconmovible de las amarguras superadas, busque estas fuentes originarias de donde brota el caudal que hoy nos nutre y que nutrirá nuestro futuro. Si ese futuro es, será español; y si no, no será" (p. 130) .

${ }^{6}$ Acerca de la revisión galdosiana que plantearon estas dos escritoras, Thion Soriano (2008) escribió lo siguiente: "Si de un hecho han alardeado algunos escritores del 27 es de haber redescubierto a Benito Pérez Galdós, en particular, Rosa Chacel y María Zambrano desde la señera revista Hora de España en 1937-1938, cuando se enjuiciaba la novelística galdosiana como completamente trasnochada pero apremiaba la necesidad de buscar referentes y valores patrios y heroicos" (p. 595). 
Zambrano, por lo demás, abrirá su ensayo de 1938 con una contextualización que indicará desde dónde surge la obra galdosiana (desde la revisión de la historia española del siglo XVIII) y cuál es el resultado trascendente de toda esa laboriosa faena de escritura y pensamiento: "De este remolino ensangrentado que es la vida española del xIx, lo que Galdós nos da es la vida misma. La vida del español anónimo, de oscuro nombre genérico" (2014, p. 569). Zambrano entiende, al igual que Chacel, que la "huella viva" de España se ha posado en las páginas galdosianas, ese "protoplasma hispánico", de cuya comprensión y codificación podría bien surgir la solución para los conflictos del momento. Hacia 1938 Zambrano explica de este modo el drama verdadero de España plasmado y proyectado vívidamente en las páginas de Misericordia:

En Misericordia hallamos, sí, un tejido social en que se entrecruzan la vena popular creadora en toda su divina potencia y lo que un instante más allá va a ser la negra sombra de Caín, pero que no lo es todavía. Un motivo más para que nuestros ojos recorran las páginas de este genial libro, que si por una parte es el "evangelio" de nuestra fuerza, de nuestra gracia más verdadera; por otra, insinúa ya su contrario, que todavía no es más que algo que ofrece resistencia sin mover aún hacia guerra. Pero la guerra está al acecho (p. 579).

\section{Conclusiones}

Hemos buscado el lugar que ocuparía el volumen La España de Galdós no únicamente dentro de la obra de María Zambrano, sino también en un contexto mucho más amplio y abarcador: las reflexiones acerca de la obra galdosiana a lo largo de una época determinada. De este modo, hemos visto cómo las percepciones y la metodología de la filósofa contrastan con aquellas que podríamos encontrar en las publicaciones y en los comentarios elaborados por los intelectuales de las distintas generaciones que reflexionaron y escribieron durante la vida de nuestra autora acerca de este mismo tema. Esto nos ha servido para recordar la indudable originalidad de sus planteamientos críticos; es cierto, sin embargo, que no hemos ahondado en todas las propuestas de la escritora debido a la delimitación del espacio. Valdría la pena seguir ese camino, si bien el análisis de 
sus ideas a veces pueda resultar, por principio de cuentas, difícil por lo rico y complejo de su inagotable discurso. Como lo anotó su editor Jesús Moreno Sanz (1993, p. xiii), el pensamiento de Zambrano "es siempre el discurrir de una serpenteante espiral". La intención por ahora ha sido empezar a entender cuál sería la relevancia del trabajo de Zambrano, sobre todo bajo la consideración, como lo hemos recordado, de que la obra de Galdós alcanzó un reconocimiento con muchos altibajos después de su muerte ocurrida en 1920; y que, por tanto, esa vehemente atención puesta en las novelas del canario resulta, sin duda, llamativa. Zambrano escoge comentar la obra de un escritor en apariencia incomprendido y supuestamente superado por las nuevas generaciones literarias. Y al hacerlo, lo coloca además en una posición excepcional: como fruto superior de la tradición artística hispánica.

Es notable entonces el hecho de que Zambrano haya publicado en 1938, durante la etapa final de la Guerra Civil española, un lúcido ensayo que revoluciona la forma en que se puede leer y valorar la obra del escritor canario desde una perspectiva enteramente personal, buscando sobre todo en las páginas de la preferida Misericordia una vía distinta que permitiese al hombre español reconciliarse consigo mismo y con su compleja historia, es decir, proponiendo la lectura de la novela de Galdós desde una perspectiva incluso, si se quiere, terapéutica, como una suerte de remedio que aliviaría los males históricos, como una guía, según el concepto planteado por la autora en diversos pasajes. La lectura de Zambrano llega todavía más lejos al plantear que "el mundo de Misericordia es ya una lucha entre la generosa prodigalidad popular y la rencorosa inhibición, el miedo a la vida” (p. 578). Es difícil, al leer este pasaje, no reconocer un fuerte eco de las concepciones orteguianas en torno a la "razón vital", pero desde una dimensión en que lo popular se privilegia como el componente netamente radical.

Ha sido importante en las páginas anteriores revisar el valor que para Zambrano tuvo la obra de Galdós en su pensamiento y contrastar, asimismo, la escasa trascendencia que Miguel de Unamuno y José Ortega y Gasset le concedieron. Si bien son muchas las lecciones aprendidas gracias al trato y a la lectura concienzuda de estos dos maestros, no por ello la escritora dejará de recorrer un camino propio, sobre todo al dedicarse al estudio del novelista. Ese camino, por ejemplo, toma derrotero distinto al seleccionar una novela de Galdós, Misericordia, 
como punto de partida para una reflexión profunda y minuciosa y reiterativa acerca de algunos de los temas fundamentales de la filosofía española y del pueblo español y de sus circunstancias históricas. Hemos tomado en cuenta las metodologías compartidas por los intelectuales cuando se acercaron a los textos literarios como trampolines para el pensamiento, pero también hemos constatado las fuertes diferencias en los análisis. Los estudios que dedica Zambrano a Galdós son netamente renovadores por todo aquello que la filósofa encuentra entre líneas y que va compartiendo con sus lectores. En este sentido, las páginas escritas por Pérez Galdós son sencillamente una incitación para encontrar en ellas eso que el escritor canario, por principio de cuentas, claramente no puso en su texto, pero que Zambrano puede encontrar allí. Misericordia podría, a primera vista, parecer una novela acerca de una criada que se esfuerza por satisfacer las necesidades de su paupérrima ama; pero en la lectura analítica y profunda de Zambrano, guiada siempre por la razón poética, se transforma en una suerte de rica exposición acerca de la forma en que puede enfrentarse la existencia -con una conducta irreprochable- en un entorno difícil y frustrante como lo sería el de la España de la Restauración borbónica. Zambrano pudo, con gran acierto, percibir en el personaje de Nina una excepcionalidad por su conducta, por su personalidad y por su disposición para solucionar los problemas inmediatos de la vida -por medio de una misericordiosa disposición. Como lo ha visto Ana Bundgård (2000, p. 376),

Nina es un personaje-guía que señala el camino de la verdad a quienes la rodean y crea utopías, soñando mentiras que "muchas veces resultan realidad" y, aunque no cree en que la justicia social exista realmente, sí cree en el poder de transformación del sueño creador y de las mentiras "nacidas" de la esperanza. Nina, persona y no personaje, tiene fe en la posibilidad de una verdadera historia viviente que desintegre la falsa historia del individuo que se despliega, dice Zambrano, entre los polos de la novela y la tragedia.

Ha sido imposible dejar de incluir el siguiente dato durante la preparación y redacción del presente trabajo: la escritura de los diversos textos acerca de Galdós ocurre y se gesta a lo largo de las distintas etapas de la vida de la autora como una constante irrenunciable en su quehacer y en sus meditaciones. 
En gran medida, esto nos puede servir para constatar la construcción de un diálogo que se inicia y que se retoma con la intención de volver siempre a la misma materia reflexiva, pero con la evidente intención de complementar, retomar y expandir las nociones previamente expuestas, pues, en apariencia, la reflexión tiende a ser interminable, infinita; las diversas ediciones que sufren los textos de La España de Galdós dan fe de ello. Esto tiene que ver con la metodología de escritura y de pensamiento de Zambrano: las multiplicaciones de los hallazgos a partir del registro de las variantes descubiertas, los complementos y la plasmación de las metáforas y de las imágenes con que se entiende mejor un tema y con que, paralelamente, se complica y se oscurece su exposición literaria. No es raro, por lo mismo, que los textos más recientes se vuelvan más problemáticos para su comprensión, su análisis y su esforzado comentario, puesto que vienen acompañados por las observaciones más recientes y por una recontextualización de lo previamente dicho (piénsese, por ejemplo, en el acomodo de los textos en La España de Galdós, el cual no sigue un criterio estrictamente cronológico).

Misericordia y la compleja figura de Nina son el corazón de su reflexión galdosiana. Este ejercicio de amorosa compenetración es el resultado palpable, sin duda, de la razón poética como concepto que guía las lecturas de Zambrano. Tendremos entonces en La España de Galdós un ejemplo avasallante que demuestra las posibilidades de embarcarse en ese proyecto que consiste en encontrar las raíces de la filosofía española no en los tratados, ni tampoco en los modelos teóricos y sistemáticos o dogmáticos, sino en las "formas sacramentales", como las definió la escritora: la poesía y la novela. En este caso, en un texto puramente novelístico en que se representa un trozo de la vida española que, sin embargo, ilustrará con suficiencia, por un lado, las limitaciones de una época más bien mediocre, y las posibilidades heroicas y picarescas, por otro, de la deslumbrante Nina de Casio, una "vida anónima con infinitas raíces".

\section{REFERENCIAS}

Azorín (José Martínez Ruiz) 1938. "Galdós”, en Lecturas españolas, Austral, Madrid, pp. 126-130.

Bergamín, José 1933. “Galdós, redimuerto”, El Heraldo de Madrid, 5 de enero. 
BundGÅRD, ANA 2000. Más allá de la filosofía: sobre el pensamiento filosófico-místico de María Zambrano, Trotta, Madrid.

Cernuda, Luis 1994 [1954]. "Galdós”, en Obra completa. Prosa I. Eds. Derek Harris y Luis Maristany, Siruela, Madrid, t. 2, pp. 517-523.

Cernuda, Luis 1999 [1962]. Desolación de la Quimera, 4ª ed. Ed. Luis Antonio de Villena, Cátedra, Madrid. [Obra precedida en esta edición por Las nubes].

Chacel, Rosa 1977. "Un hombre al frente: Galdós”, en Hora de España. Ed. facs. con introd. de Enrique Montero, Topos Verlag AG-Laia, Barcelona, t. 1 , pp. 47-50.

Chica, Francisco 1999. “"Un cielo sin reposo». Emilio Prados y María Zambrano: correspondencia(s)”, en Homenaje a María Zambrano. Eds. Rose Corral, Anthony Stanton y James Valender, El Colegio de México, pp. 199-259.

Cruz Ayuso, María Cristina de la 1999. "María Zambrano y la Misericordia: una aproximación a la obra de Galdós", Aurora. Papeles del Seminario María Zambrano, 1, pp. 125-131.

De Torre, Guillermo 1969. "Revaloración de Galdós", en Del 98 al Barroco, Gredos, Madrid, pp. 165-232.

Espina, Antonio 1923. "Libros de otro tiempo: Benito Pérez Galdós. Fisonomías sociales: José María Matheu: Los tres dioses y otras narraciones”, Revista de Occidente, 1, pp. 114-117.

Gómez Blesa, Mercedes 2004. "Zambrano: más allá de la razón vital”, Revista de Occidente, 276, pp. 73-87.

Jauss, Hans Robert 2000. La historia de la literatura como provocación. Trads. Juan Godó Costa y José Luis Gil Aristu, Península, Barcelona.

Madariaga, Salvador de 1924. "Benito Pérez Galdós", en Semblanzas literarias contemporáneas. Ensayos sobre el sentido de la cultura española, Editorial Cervantes, Barcelona, pp. 67-91.

Maillard García, María Luisa 2014. "Prólogo", en María Zambrano, Obras completas. T. 3: Libros (1955-1973), $2^{a}$ ed. Eds. Jesús Moreno Sanz et al., Galaxia Gutenberg-Círculo de Lectores, Barcelona, pp. 505-513.

Mora García, José Luis 2004. "Un nombre de mujer: Misericordia. Galdós en la inspiración zambraniana”, en María Zambrano. Raíces de la cultura española. Coord. Juan Fernando Ortega Muñoz, Fundación Fernando Rielo, Madrid, pp. 119-146.

Moreno SAnz, Jesús 1993. "Introducción”, en María Zambrano, La razón en la sombra. Antología. Ed. J. Moreno Sanz, Siruela, Madrid, pp. i-xxxvii.

Morón Arroyo, Ciriaco 1966. "Galdós y Ortega y Gasset: historia de un silencio", Anales Galdosianos, 1, pp. 143-150.

ONís, FEDERICO DE 1932. "El españolismo de Galdós", en Ensayos sobre el sentido de la cultura española, Residencia de Estudiantes, Madrid, pp. 111-120.

Ontañón de Lope, Paciencia 1999. "Las innovaciones de Galdós y las repercusiones en la Generación del 98”, Anuario de Letras, 37, pp. 225-248.

Ortega y Gasset, José 1914. Vieja y nueva política, Renacimiento, Madrid.

Ortega y Gasset, José 1977. Origen y epílogo de la filosofía, 2a ed., Fondo de Cultura Económica, México.

Ortega y Gasset, José 2007 [1921]. España invertebrada. Bosquejos de algunos pensamientos históricos, Folio, Barcelona. 
Ortega y Gasset, José 2014 [1914]. Meditaciones del Quijote y otros ensayos, Alianza, Madrid.

Pérez de Ayala, Ramón 1919 [1916]. Las máscaras. T. 1: Galdós, Benavente, Linares, Rivas, Villaespesa, Morano, Imprenta Clásica Española, Madrid.

Ramírez, Goretti 2004. María Zambrano, crítica literaria, Devenir, Madrid.

Rivara Kamaji, Greta 2014. "La razón poética de María Zambrano y los arrabales matritenses de Benito Pérez Galdós: un diálogo a propósito de Misericordia", en La palabra compartida. María Zambrano en el debate contemporáneo. Coords. Sebastián Lomelí, Leonarda Rivera y Cintia C. Robles Luján, Universidad Veracruzana-Secretaría de Cultura de MichoacánMiguel Ángel Porrúa, México, pp. 73-92.

SÁnchez Benítez, Roberto 2002. "Identidad y literatura en María Zambrano”, Signos Filosóficos, 8, pp. 93-110.

SÁnchez-Gey Venegas, JuAna 1992. "Acerca de la mujer (Tristana): el Galdós de María Zambrano”, en Actas del Quinto Congreso Internacional de Estudios Galdosianos, Cabildo Insular de Gran Canaria, Las Palmas, pp. 487-493.

SÁnchez-Gey Venegas, Juana 2009. "Galdós y María Zambrano: el saber de la experiencia”, en Actas del Noveno Congreso Internacional de Estudios Galdosianos, Cabildo Insular de Gran Canaria, Las Palmas, pp. 483-491.

Tejada, Ricardo 2011. "Introducción”, en María Zambrano, Escritos sobre Ortega, Trotta, Madrid, pp. 9-59.

Thion Soriano-Mollá, Dolores 2008. "Galdós y la confesión (María Zambrano, Rosa Chacel)", en Galdós y la gran novela del XIX. IX Congreso Internacional Galdosiano, Cabildo de las Palmas de Gran Canaria-Casa Museo Pérez Galdós-Ediciones del Cabildo, Las Palmas, pp. 594-603.

Unamuno, Miguel de 1966 [1920]. "La sociedad galdosiana”, en Obras completas. Nuevos ensayos. Ed. Miguel García Blanco, Escelicer, Madrid, t. 3, pp. 1203-1204.

Unamuno, Miguel de 1966a [1920]. "Nuestra impresión de Galdós”, en Obras completas. Nuevos ensayos. Ed. Miguel García Blanco, Escelicer, Madrid, t. 3, pp. 1207-1209.

Unamuno, Miguel de 1996 [1902]. En torno al casticismo, Biblioteca Nueva, Madrid.

Zambrano, María 2009 [1986]. "Un don del océano: Benito Pérez Galdós", en Las palabras del regreso. Ed. Mercedes Gómez Blesa, Cátedra, Madrid, pp. 200-204.

Zambrano, María 2011 [1948]. "El problema de la filosofía española", en Escritos sobre Ortega, Trotta, Madrid, pp. 81-86.

Zambrano, María 2011 [1963]. "Un frustrado pliego de cordel de Ortega y Gasset", en Escritos sobre Ortega, Trotta, Madrid, pp. 170-175.

Zambrano, María 2014 [1938]. "Misericordia”, en Obras completas. T. 3: Libros (1955-1973), 2ª ed. Eds. J. Moreno Sanz et al., Galaxia Gutenberg-Círculo de Lectores, Barcelona, pp. 569-588.

Zambrano, María 2014a [1960]. La España de Galdós, en Obras completas. T. 3: Libros (1955-1973), 2ª ed. Eds. J. Moreno Sanz et al., Galaxia Gutenberg-Círculo de Lectores, Barcelona, pp. 503-609. 
Zambrano, María 2015 [1937]. "La reforma del entendimiento español", en Obras completas. T. 1: Libros (1930-1939). Eds. J. Moreno Sanz et al., Galaxia Gutenberg-Círculo de Lectores, Barcelona, pp. 205-220.

Zambrano, María 2015a [1938]. "Poesía y revolución. El hombre y el trabajo de Arturo Serrano Plaja”, en Obras completas. T. 1: Libros (1930-1939). Eds. J. Moreno Sanz et al., Galaxia Gutenberg-Círculo de Lectores, Barcelona, pp. 262-274.

Zambrano, María 2015b [1939]. Pensamiento y poesía en la vida española, en Obras completas. T. 1: Libros (1930-1939). Eds. J. Moreno Sanz et al., Galaxia Gutenberg-Círculo de Lectores, Barcelona, pp. 553-656.

Zambrano, María 2015c [1943]. Unamuno. Ed. Mercedes Gómez Blesa, Penguin Random House, Barcelona. 
